\title{
Acumulação de Capital, Restrição Externa, Hiato Tecnológico e Mudança Estrutural: Teoria e Experiência Brasileira
}

\author{
Marcos Tostes Lamonica \\ Professor Adjunto do Departamento de Economia da Universidade Federal Fluminense (UFF) \\ Endereço para contato: Rua Tiradentes, 17 - Niterói - Rio de Janeiro - CEP: 24220-510. \\ Email: marcostostes@hotmail.com
}

\section{José Luis da Costa Oreiro}

Professor do Departamento de Economia da Universidade de Brasília (UnB)

Diretor da Associação Keynesiana Brasileira.

Endereço para contato: Faculdade de Economia da UnB - Campus Darcy Ribeiro - Asa Norte, Brasília - Distrito Federal - CEP: 70910-900.

Email: jlcoreiro@terra.com.br

\section{Carmem Feijó}

Professora Associada do Departamento de Economia da Universidade Federal Fluminense (UFF) Endereço para contato: R. Tiradentes, 17 - Niterói - RJ - CEP: 24220 - 510.

Email: cfeijo@terra.com.br

Recebido em 27 de outubro de 2009. Aceito em 28 de novembro de 2011.

\section{Resumo}

Os períodos de crescimento acelerado da economia brasileira do pós-guerra até a década de 1970 foram constrangidos pela restrição externa. Propomos neste artigo um modelo baseado em Kaldor, em que estabelecemos uma relação entre acumulação de capital, hiato tecnológico e restrição externa ao crescimento de longo prazo para economias periféricas. A hipótese básica do modelo é que a acumulação de capital, sob certas condições, pode contornar a restrição externa ao crescimento dessas economias desde que o esforço de acumulação seja capaz de produzir uma mudança estrutural no sentido de aumentar a participação relativa dos setores mais dinâmicos do ponto de vista tecnológico. Essa mudança estrutural irá resultar em um aumento gradual da elasticidade-renda das exportações e numa redução da elasticidade-renda das importações, aumentando assim a taxa de crescimento do produto real que é compatível com o equilíbrio de longo prazo do balanço de pagamentos. Ilustramos ao final do artigo que a economia brasileira do pós-guerra até os anos 1970 apresentou uma elevada taxa de acumulação de capital, aprofundando o processo de substituição de importações, o que na nossa interpretação contribuiu para parcialmente permitir relaxar a restrição externa ao crescimento de longo prazo. 


\title{
Palavras-Chave
}

mudança estrutural, progresso tecnológico, industrialização, restrição externa

\begin{abstract}
The periods of fast growth in the Brazilian economy from the post-war until the end of the 1970s have been constrained by imbalances in the foreign sector. We propose in this paper a model, based on Kaldor, where capital accumulation, technological gap and long run external constrain are connected. Our hypothesis is that capital accumulation, under certain circumstances, can overcome external constrain if the accumulation effort promotes structural change increasing the importance of sectors technological-intensive. It is expected that the structural change in this direction will contribute to an increase in the income-elasticity of exports and to a decrease in income-elasticity of imports, resulting in the increase in the growth rate of real product compatible with the balance of payments equilibrium in the long run. The last part of the paper shows that the high investment rate observed in the Brazilian economy from the post-war period until the end of the 1970s resulted in the deepening of the import substitution process, what, in our interpretation, contributed to partially increase the long run growth rate of the Brazilian economy compatible with the balance of payment equilibrium.
\end{abstract}

\section{Keywords}

structural change, technological progress, industrialization, external restriction

\section{JEL Classification}

$\mathrm{F} 43, \mathrm{O} 11$

\section{Introdução}

O desenvolvimento econômico é definido, na tradição estruturalista latino-americana, como um processo de aumento contínuo da renda per capita impulsionado pelo crescimento da produtividade do trabalho, o qual resulta da adoção de métodos indiretos de produção, ou seja, métodos nos quais se incrementa a divisão técnica do trabalho entre atividades, o que, por seu turno, supõe o aumento da quantidade de capital por trabalhador (Rodriguez, 2009, p.80). Em outras palavras, o desenvolvimento econômico decorre do progresso técnico que é induzido ou viabilizado pela acumulação de capital.

Esse processo, no entanto, não é analisado do ponto de vista de uma economia capitalista modelo, mas pressupõe a existência de diferenças estruturais importantes entre as economias capitalistas, as quais permitem definir a existência de um "centro" e uma "periferia" no capitalismo mundial. As economias centrais são aquelas em que as 
técnicas mais avançadas de produção penetram primeiro; ao passo que a periferia é constituída por economias cuja produção permanece atrasada, quer do ponto de vista tecnológico, quer do ponto de vista organizacional (Ibid, p.81). Nesse sentido, com respeito ao crescimento econômico, Furtado [1952] diz que "o crescimento de uma economia desenvolvida é [...] de acumulação de novos conhecimentos científicos e de progressos na aplicação desses conhecimentos. O crescimento de economias subdesenvolvidas é, sobretudo, um processo de assimilação da técnica prevalecente na época". (Ibid; 2010, p 336).

No caso brasileiro, analisado como economia periférica, Furtado (1984) aponta que "nossa industrialização tardia foi conduzida no quadro de um desenvolvimento inativo" (Ibid, p.27), onde o processo de acumulação serviu a um tipo de modernização que reproduzisse um padrão de consumo do centro, "privando a grande maioria da população de bens e serviços essenciais" (Ibid, p.29). Portanto, "a reprodução, mediante a industrialização substitutiva de importações, das estruturas sociais modernizadas tende a perpetuar a dependência tecnológica" (Ibid, p.116). Nesse contexto, o modelo de desenvolvimento empregado pelas economias periféricas da América Latina privilegiou a importação de tecnologia, invés do desenvolvimento de uma tecnologia local. Segundo Fajnzylber (1983), quando se cria uma indústria desprovida de um "núcleo endógeno de dinamização tecnológica" não se poderia superar a vulnerabilidade externa pertinente às economias periféricas. Nessa percepção, a inexistência ou insuficiência de uma estrutura científica e tecnológica integrada e ligada ao sistema produtivo geraria assimetrias tecnológicas, mantendo a relação centro versus periferia.

Assim, pode-se constatar a existência de assimetrias tecnológicas importantes entre as economias capitalistas, assimetrias essas que permitem a caracterização de um hiato tecnológico. Esse hiato tecnológico seria a razão fundamental pela qual o crescimento da produtividade - e, por conseguinte, da renda per capita - é mais baixo na periferia do que no centro, dando origem a um desenvolvimento desigual entre as mesmas.

Nesse contexto, a eliminação do hiato tecnológico é condição necessária para que as economias subdesenvolvidas ou periféricas possam fazer o processo de catching-up com respeito às economias desenvolvidas ou centrais. Por suposto, como o progresso técnico é, 
em larga medida, incorporado em novas máquinas e equipamentos, a redução do hiato tecnológico pressupõe um esforço de acumulação de capital maior por parte das economias periféricas do que nas economias centrais.

No entanto, a estrutura produtiva especializada e heterogênea das economias periféricas pode atuar como um empecilho à realização desse maior esforço de acumulação. Isso porque as economias periféricas são especializadas na produção de bens primários com vistas à exportação. As necessidades de consumo de bens duráveis e de investimento dessas economias são atendidas pelas importações feitas das economias centrais. Como a elasticidade-renda das exportações desses produtos é, via de regra, baixa, ao passo que a elasticidade-renda das importações de bens manufaturados é alta (Prebisch, 2000, p 185), segue-se que o equilíbrio de longo prazo do balanço de pagamentos impõe que as economias periféricas cresçam a um ritmo mais baixo do que as economias centrais.

A condição periférica se reproduz, assim, de forma dinâmica, recriando, mesmo com a industrialização, como disse Fajnzylber (1983), os desequilíbrios internos e externos. Para Tavares (1976), entre outros, "o estrangulamento externo só era indutor do processo de desenvolvimento, à medida que havia internamente uma demanda contida por importações de bens de consumo que ao serem substituídas expandiam o próprio mercado interno e geravam uma demanda derivada de bens de capital e produtos intermediários, [que] resultava em novo estrangulamento externo levando a uma outra onda de substituição, e assim por diante" (Ibid, p.117).

Segue-se, portanto, que a restrição externa imposta pela estrutura produtiva dos países periféricos atua no sentido de reforçar e perpetuar o hiato tecnológico à medida que impede a sustentação de um maior esforço de acumulação de capital por parte desses países. Como colocado por Fajnzylber (1983), o desenvolvimento econômico, decorrente do aprofundamento da industrialização, seria baseado em um 'crescimento com criatividade', isto é, a acumulação de capital carece da inovação tecnológica. Isso posto, o objetivo do presente artigo é analisar a relação entre acumulação de capital, hiato tecnológico e restrição externa ao crescimento de longo prazo das economias periféricas. A hipótese básica deste trabalho é que a acumulação de capital, sob certas condições, pode contornar a restrição externa ao 
crescimento dessas economias desde que o esforço de acumulação seja capaz de produzir uma mudança estrutural nessas economias, ou seja, induza uma transformação na estrutura produtiva das economias periféricas, no sentido de aumentar a participação relativa dos setores mais dinâmicos do ponto de vista tecnológico. Essa mudança estrutural irá resultar num aumento gradual da elasticidade-renda das exportações e numa redução da elasticidade-renda das importações, aumentando assim a taxa de crescimento do produto real, que é compatível com o equilíbrio de longo prazo do balanço de pagamentos. ${ }^{1}$

A consistência lógica dessa argumentação será realizada por intermédio de um modelo de crescimento do tipo Kaldoriano no qual: (i) o investimento em modernização do equipamento de capital permite a absorção de novas tecnologias, possibilitando assim a produção de bens com conteúdo tecnológico crescente; (ii) a incorporação de novas tecnologias induz uma mudança estrutural na economia, a qual permite um aumento da elasticidade-renda das exportações e uma redução da elasticidade-renda das importações. Por fim, apresentase o caso da economia brasileira no período 1950-1980 como comprovação histórica da tese de que um maior esforço de acumulação de capital pode induzir uma mudança estrutural de tal ordem que permita um relaxamento da restrição externa ao crescimento de longo prazo.

O presente artigo está organizado em sete seções, incluindo a presente introdução. Na seção 2, apresentamos a relação entre restrição externa e crescimento de longo prazo, a partir da literatura póskeynesiana de crescimento com restrições do balanço de pagamentos. Na seção 3 desenvolvemos um arcabouço teórico-conceitual, que relaciona a mudança estrutural com a restrição externa. Esse arcabouço é desenvolvido a partir das contribuições das literaturas evolucionária e estruturalista latino-americana. Na seção 4 apresentamos a relação entre acumulação de capital e progresso tecnológico a partir do modelo de crescimento de Kaldor-Mirrlees. Na seção 5 apresentamos um modelo de crescimento híbrido que integra a restrição externa e o investimento em modernização do equipamento de capital num contexto de mudança estrutural. Na seção 6 discutimos o caso da

1 Dentro dessa perspectiva analítica deve ser mencionada a contribuição de Araújo e Lima (2007), que também concordam que a "mudança estrutural pode afetar as elasticidadesrenda das importações e exportações e, portanto, a taxa de crescimento em uma estrutura Kaldor-Thirlwall" (p 757). 
economia brasileira no período 1950-1980 como um exemplo bemsucedido de mudança estrutural induzido pelo esforço de acumulação de capital, o que permitiu um relaxamento, ainda que parcial e temporário, da restrição externa ao crescimento. Por fim, na seção 7 fazemos uma reprise das conclusões deste trabalho.

\section{Restrição Externa ao Crescimento de Longo Prazo}

A restrição externa ao crescimento de longo prazo tem sido analisada, entre outros, por Thirlwall $(1979,1997,2001)$. O conceito de taxa de crescimento de equilíbrio do balanço de pagamentos foi desenvolvido por esse autor a partir da constatação de que os modelos de crescimento de causalidade cumulativa de inspiração Kaldoriana, nos quais a taxa de crescimento da demanda de exportações é o motor fundamental do crescimento econômico de longo prazo, são incompletos por não incluírem em sua estrutura analítica formal uma condição de equilíbrio do balanço de pagamentos. Dessa forma, a depender do valor da elasticidade-renda das importações, uma trajetória de crescimento acelerado puxado por um forte ritmo de expansão das exportações pode gerar um déficit comercial crescente ao induzir um crescimento insustentável das importações. Sendo assim, define-se a taxa de crescimento de equilíbrio do balanço de pagamentos como:

(...) The growth rate consistent with the equilibrium in the current account of the balance of payments assuming that deficits cannot be financed forever and debt has to be repaid. (Thirlwall, 2001, pp.81-82)

Uma formalização simples do conceito de taxa de crescimento de equilíbrio do balanço de pagamentos pode ser obtida em Atesoglu (1997), sendo reproduzida a seguir. Considere uma economia descrita pelo seguinte sistema de equações:

$$
\begin{aligned}
& \log M_{t}+\log P m_{t}=\log X_{t}+\log P x_{t} \\
& \log M_{t}=\pi \log Y_{t}+\phi\left(\log P x_{t}-\log P m_{t}\right)
\end{aligned}
$$


Onde: $M_{t}$ é o quantum importado no período $t ; X_{t}$ é o quantum exportado no período $t$; $Y_{t}$ é o produto real doméstico no período $t ; \mathrm{Pm}_{t}$ é o preço dos bens importados no período $t ; P x_{t}$ é o preço dos bens exportados no período $t$; $\pi$ é a elasticidade-renda das importações; $\phi$ é a elasticidade-preço das importações.

A Equação (1) apresenta a condição de equilíbrio do balanço de pagamentos na ausência de fluxos de capitais externos. Por sua vez, a Equação (2) apresenta o quantum importado como uma função da renda doméstica e dos termos de troca. Deve-se destacar que, por simplicidade, assume-se a taxa de câmbio como fixa e igual a um.

Substituindo (1) em (2) e considerando $\left(\log P x_{t}-\log P m_{t}\right)=0^{2}$, obtemos:

$$
\log Y_{t}=\frac{1}{\pi} \log X_{t}
$$

A Equação (3) apresenta o produto real doméstico como uma função do quantum exportado pela economia no período $t$; uma relação conhecida como o multiplicador do comércio exterior de Harrod (1933). Diferenciando a Equação (3), temos:

$$
\frac{\dot{Y}_{t}}{Y_{t}}=\frac{1}{\pi} \frac{\dot{X}_{t}}{X_{t}}
$$

e lembrando que a taxa de crescimento das exportações $x_{t}$ é definida por:

$$
x_{t}=\frac{\dot{X}_{t}}{X_{t}}
$$

e que pode ser dada por:

$$
x_{t}=\varepsilon \cdot z_{t}
$$

Onde $\varepsilon$ é a elasticidade-renda das exportações e $z_{t}$ é a taxa de crescimento da renda externa definida como:

2 Cf. Atesoglu, 1997, p. 331. 


$$
z_{t}=\frac{\dot{Y}_{t}^{*}}{Y_{t}^{*}}
$$

Podemos considerar que a taxa de crescimento da renda interna definida como:

$$
y_{t}=\frac{\dot{Y}_{t}}{Y_{t}}
$$

Substituindo as Equações (5), (6), (7) e (8) em (4), encontramos a taxa de crescimento da renda interna que é compatível com o equilíbrio do balanço de pagamentos.

$$
y_{t}=\frac{\varepsilon_{t}}{\pi_{t}} z_{t}
$$

Neste caso, chamamos $y_{t}$ de taxa de crescimento de equilíbrio do balanço de pagamentos. A Equação (9) é conhecida na literatura como "lei de Thirlwall". Esta lei, assim representada, pressupõe que a mobilidade internacional de capitais é igual a zero, de forma que os países não podem se endividar para financiar os déficits em conta-corrente. A extensão do modelo de Thirlwall para uma economia com fluxos de capitais foi feita, entre outros, por Moreno-Brid (1998-1999). No modelo de Moreno-Brid admite-se a existência de fluxos internacionais de capitais, mas a dinâmica do endividamento externo tem que atender a condição de solvência externa de longo prazo. Em particular, o modelo desenvolvido por este autor assume que a relação entre o déficit em conta corrente e a renda doméstica deve permanecer constante no longo prazo para que o país seja solvente do ponto de vista de suas contas externas. Assumiremos nesse trabalho que o déficit em conta- corrente tem impacto negligenciável sobre a taxa de crescimento compatível com o equilíbrio do balanço de pagamentos (McCombie e Roberts; 2002, p.94). Sendo assim, a Equação (9) será considerada uma boa aproximação da restrição externa ao crescimento econômico de longo prazo. Também podemos considerar até aqui que a acumulação de capital não afeta $y_{t}$, pois $\varepsilon$ e $\pi$ dependem apenas da estrutura produtiva. 


\section{Mudança Estrutural e Restrição Externa}

A taxa de crescimento que é compatível com o equilíbrio do balanço de pagamentos depende, como foi visto, da elasticidade-renda das exportações e das importações, as quais dependem, por sua vez, da estrutura produtiva da economia. Países desenvolvidos e em desenvolvimento possuem estruturas produtivas diferentes, as quais refletem diferenças fundamentais na sua capacitação tecnológica, ou seja, na sua capacidade tanto de produzir conhecimento tecnológico, como na sua capacidade de imitar conhecimento tecnológico desenvolvido em outras partes do mundo (Verspagen; 1993, p.126).

Essas diferenças na capacitação tecnológica se refletem numa maior participação dos setores dinâmicos tecnologicamente na estrutura produtiva dos países desenvolvidos do que nos países em desenvolvimento. Dessa forma, os países desenvolvidos possuem um número maior de setores de atividade nos quais as firmas operam na assim chamada "fronteira tecnológica". Sendo assim, a sua pauta de exportações será formada majoritariamente por produtos de alto valor adicionado e alto conteúdo tecnológico, produtos para os quais a elasticidade-renda das exportações é elevada. Daqui se segue que o assim chamado gap ou hiato tecnológico ${ }^{3}$ é um determinante importante da elasticidade-renda das exportações e, portanto, da taxa de crescimento que é compatível com o equilíbrio do balanço de pagamentos (Dosi, Pavitt e Soete; 1990, p.26). Como corolário dessa argumentação segue-se que a taxa de crescimento que é compatível com o equilíbrio do balanço de pagamentos tende a ser maior nos países desenvolvidos do que nos países em desenvolvimento. ${ }^{4}$

O baixo dinamismo tecnológico de muitos países em desenvolvimento, notadamente na América Latina, explica a debilidade dos impulsos ao crescimento proporcionados pela expansão das demandas internas e externas (Holland e Porcile; 2005, p.42). Para que os países em desenvolvimento possam reduzir a restrição externa ao crescimento é necessário que os mesmos sejam capazes de realizar

Sobre o conceito de hiato tecnológico ver Fagerberg (1988).

A partir de um modelo econométrico de crescimento e comércio Norte-Sul, Dutt (2003) mostra que a elasticidade-renda das exportações dos países do Norte para os países do Sul (ou seja, a elasticidade-renda das importações dos países do Sul) no período 1964-1995 é de 1,67; ao passo que a elasticidade-renda das exportações dos países do Sul para os países do Norte é de 1,27. Dessa forma, a razão entre as duas elasticidades mostra que, em equilíbrio de longo prazo, os países do Sul deverão crescer menos do que os países do Norte, gerando assim uma dinâmica de divergência de rendas per capita no longo prazo. 
mudanças na sua estrutura produtiva. ${ }^{5}$ Essas mudanças devem ser capazes de promover alterações nas elasticidades-renda da demanda dos produtos exportados de modo a reduzir o grau de exposição a desequilíbrios externos.

\subsection{Mudança Estrutural, Padrão de Especialização e Hiato Tecnológico}

A mudança estrutural pode ser promovida por um esforço de acumulação de capital que conduziria, via modernização e atualização do estoque de capital, a uma redução do hiato tecnológico. Isso porque, tal como ressaltado por Kaldor (1957), uma parte significativa do "progresso tecnológico" está incorporada em novas máquinas e equipamentos, de tal forma que um maior esforço de acumulação de capital significa também um maior esforço no sentido de adquirir e incorporar novas tecnologias. Daqui se segue que a dinâmica do hiato tecnológico depende, entre outras variáveis, do ritmo de acumulação de capital. Nesse contexto, um maior esforço de acumulação de capital irá atuar no sentido de reduzir o hiato tecnológico e, dessa forma, aumentar o conteúdo tecnológico das exportações, promovendo assim um aumento na taxa de crescimento das exportações e na taxa de crescimento compatível com o equilíbrio no balanço de pagamentos.

Segundo Dosi, Pavitt e Soete (op.cit., p.199), o padrão de crescimento de uma economia está relacionado ao padrão de mudança tecnológica. Assim, considerando o desempenho relativo dos países e considerando a restrição do balanço de pagamentos, o nível relativo de tecnologia aplicada à produção não só determina o nível de renda de cada país como também afeta as possibilidades de crescimento e a taxa de acumulação de capital.

O nível de desenvolvimento tecnológico está relacionado ao padrão de especialização do país. Economias especializadas em setores de

5 Deve se ressaltar que a distinção entre centro e periferia não é plenamente equivalente à diferença entre estruturas produtivas diversificadas e especializadas. A característica fundamental do centro é a capacidade de geração de tecnologia up-to-date. Sendo assim, a existência de uma estrutura produtiva diversificada, como a existente, por exemplo, nos países do sudeste asiático, não é condição suficiente para torná-los países centrais. Isso porque esses países ainda carecem de capacidade própria de geração de novas tecnologias. No entanto, a diversificação de estrutura produtiva é uma condição necessária, embora não suficiente, para redução do hiato tecnológico. 
baixa elasticidade-renda da demanda estão mais expostas a desequilíbrios externos que se traduzem em taxas de crescimento do produto mais baixas.

Por intermédio do desenvolvimento da capacidade tecnológica, o lançamento de novos produtos, representando uma inovação no mercado internacional, possibilita a expansão das exportações, que por sua vez, compensaria níveis mais altos de importações devido ao aumento da renda e consequentemente níveis mais altos de demanda gerada endogenamente. Mas a inovação depende do investimento em conhecimento e sua posterior materialização em bens intermediários e bens de consumo final. O surgimento de novos produtos e setores é fruto da mudança tecnológica, que por sua vez explica as mudanças estruturais. As economias que são capazes de desenvolver e absorver novas tecnologias conseguem modificar a composição setorial de sua indústria e difundir as mudanças tecnológicas para todo o resto da economia (Cimoli et al., 2005, p 12).

A existência de recursos naturais e trabalho em quantidades abundantes pode sustentar altas taxas de crescimento durante um certo período, sem que seja necessário um grande esforço de investimento em conhecimento tecnológico. Porém, a disponibilidade de recursos naturais é, em si mesma, insuficiente para sustentar o crescimento de longo prazo. E isto ocorre por duas razões: a primeira é que o crescimento baseado em fatores abundantes não promove a mudança estrutural e aumentos de produtividade no conjunto da economia e reproduz situações indesejadas de desigualdade distributiva, má qualidade dos empregos e heterogeneidade estrutural; em segundo lugar, a vulnerabilidade do crescimento frente às mudanças na economia internacional e nos padrões de demanda é mais elevada quando o padrão de especialização da economia é baseado em recursos naturais. Quando as bases de crescimento são as rendas geradas pela tecnologia e conhecimento, esses mesmos conhecimentos são um instrumento que permite responder a mudança no ambiente competitivo. Inversamente, quando a fonte de renda é muito dependente de um recurso abundante, falta a capacidade tecnológica necessária para readaptar a economia a novos contextos competitivos (Cimoli et al., op.cit, p.32-33).

Nesse sentido, a redução do hiato tecnológico requer que, no longo prazo, as economias sejam capazes de transformar sua estrutura pro- 
dutiva, de um padrão de crescimento baseado nas rendas derivadas da abundância de algum fator de produção, a outro baseado nas rendas geradas por tecnologia. Nessa transformação, espera-se que os setores mais dinâmicos e difusores de conhecimento alcancem um peso crescente na estrutura produtiva. Os efeitos dinâmicos entre os setores, assim como sua relação virtuosa com o investimento em tecnologia, são necessários para combinar o rápido crescimento da produtividade com taxas elevadas de emprego na economia, reduzindo a heterogeneidade estrutural que é característica de países em desenvolvimento. Segundo Cimoli et al. (op. cit., p.33), em economias com pouca mudança estrutural, incrementos localizados da produtividade são de pouca ajuda para reduzir a informalidade e a heterogeneidade.

$\mathrm{Na}$ medida em que os países menos desenvolvidos realizam esforços próprios no sentido do incentivo tecnológico, as tecnologias ou o estoque de equipamento de capital vão se tornando mais padronizados, e a desvantagem tecnológica no comércio internacional se reduz e outros fatores de competitividade ganham mais importância do que os custos de produção relacionados com a disponibilidade de mão de obra e recursos naturais.

Como apontado por Fajnzylber (1983, e 2000), por exemplo, Holland e Porcile observaram a experiência internacional de crescimento econômico entre 1990 e 2003, e concluíram que a redução (ou eliminação) da heterogeneidade estrutural, assim como a convergência da renda per capita interna à prevalecente no resto do mundo dependem de um esforço sustentado de cada país para fortalecer suas capacidades tecnológicas. Com efeito, o aprendizado tecnológico pode gerar em longo prazo um incremento na capacidade tecnológica. Um possível corolário da redução da heterogeneidade estrutural é a mudança na estrutura produtiva no sentido de diversificar as exportações para bens de maior dinamismo tecnológico e de demanda (Ibid, p.60).

Portanto, a redução do hiato tecnológico induz à redução da heterogeneidade estrutural e ao aumento da taxa salário do país em desenvolvimento vis-à-vis ao desenvolvido. Dessa forma, a convergência internacional - catching up - requer o aumento da capacidade tecnológica nos países mais atrasados de tal forma a reduzir sua distância com relação à fronteira tecnológica (Ibid, p.57). 
No desenvolvimento do modelo que será apresentado na próxima seção, o hiato tecnológico vai ser representado como uma função da diferença entre a idade média do estoque de capital no país atrasado relativamente à fronteira, ${ }^{6}$ supondo que o estoque de capital da economia periférica é mais antigo que na fronteira. Essa proxy tem obviamente as suas limitações, haja vista que a idade média do equipamento de capital, ainda que possa ser uma variável importante na difusão do progresso técnico da fronteira para a periferia, não guarda nenhuma relação direta com a capacidade de geração de novas tecnologias. Em outras palavras, a compra de equipamento de capital recentemente produzido ajuda no processo de transferência de tecnologias já existentes na fronteira para a periferia, mas não contribui para a geração de conhecimento tecnológico up-to-date nos países periféricos. Sendo assim, a redução da idade média do equipamento de capital poderá contribuir para a redução do hiato tecnológico apenas até certo ponto, a partir do qual se fará necessária a geração de um esforço próprio de pesquisa e desenvolvimento de novas tecnologias.

Isso posto, o objetivo do modelo a ser apresentado é mostrar como a modernização do estoque de capital doméstico vis-à-vis o externo pode contribuir para a redução do hiato tecnológico, e assim obter uma aceleração da taxa de crescimento compatível com equilíbrio no balanço de pagamentos.

\section{O Investimento na Modernização do Estoque de Capital: Um Modelo Kaldoriano}

A partir das discussões apresentadas nas seções anteriores, podemos avançar a hipótese teórica de que o investimento em equipamento de capital de última geração precede temporalmente a mudança estrutural, tendo em vista que (i) o progresso tecnológico está incorporado em novas máquinas e equipamentos; (ii) existe um hiato tecnológico não desprezível entre os países desenvolvidos e em desenvolvimento e (iii) existe uma relação entre o hiato tecnológico e a estrutura produtiva dos países em desenvolvimento. Dessa forma, concluímos que a mudança estrutural resulta de um processo acelerado de acumu-

${ }^{6}$ Segundo Verspagen (1993, p.128), o hiato tecnológico implica uma relação entre as capacidades tecnológicas entre um certo país e a fronteira tecnológica. Dessa forma, o mesmo é definido como: $\mathrm{G}=\mathrm{Tn} / \mathrm{Ts}$, onde $\mathrm{T}$ é a capacidade tecnológica do norte (n) ou do sul (s). 
lação de capital no qual os empresários do país em desenvolvimento adquirem novos equipamentos de capital, aumentando assim a sua capacitação tecnológica, a qual atua no sentido de reduzir o hiato tecnológico.

Para dar um tratamento mais formal a essa ideia, iremos introduzir a perspectiva de análise do modelo Kaldor e Mirrlees (1962) no contexto dos modelos de crescimento com restrição do balanço de pagamentos. A ideia do investimento em equipamento de capital de última safra do modelo de Kaldor-Mirrlees pode ser introduzida no modelo apresentado na seção II; associando-se à dependência das elasticidades-renda das importações e das exportações à idade média do estoque de capital da economia. Ao elaborarmos analiticamente essa associação (seção 5) estaremos fazendo uma conexão entre a taxa de crescimento compatível com o equilíbrio no balanço de pagamentos à taxa garantida de crescimento. Portanto, a partir desse suposto, um esforço de acumulação de capital poderia atuar no sentido de relaxar a restrição externa.

O modelo de crescimento desenvolvido por Kaldor e Mirrlees (1962) parte da abordagem keynesiana tradicional, na qual as decisões de investimento dos empresários têm papel fundamental no crescimento do produto. Em A New Model of Economic Growth, o progresso técnico é tratado de forma explícita como uma taxa de modernização da máquina da nova "safra", como o principal determinante do crescimento econômico. ${ }^{7}$

O modelo Kaldor-Mirrlees sustenta que em cada período serão produzidas máquinas mais produtivas do que as do período anterior. Sendo assim, as máquinas produzidas hoje têm um nível de eficiência técnica superior às produzidas ontem. Ou seja, o capital da safra atual tem uma produtividade superior ao das safras anteriores. Esta suposição se deve ao fato de a última tecnologia disponível vir incorporada na máquina da última safra. A hipótese teórica do modelo é que máquinas de uma determinada safra têm eficiência física constante ao longo de sua vida útil, ou seja, suas produtividades não se alteram, mas cada máquina de uma safra mais nova tem um nível de produtividade superior a anterior.

7 Ver também Kaldor (1957). 
Entretanto, a máquina pode ser retirada antes do término de sua vida útil devido à 'obsolescência tecnológica'. ${ }^{8} \mathrm{~A}$ condição mínima para manter o equipamento em operação é quando a receita gerada pelo trabalhador ao operar este equipamento $\left(P_{t-T}\right)$ é exatamente igual a sua remuneração, isto é o salário $(W)$, ambos em termos reais:

$$
P_{t-T}=W_{t}
$$

A Equação (10) indica o momento em que a máquina deixa de gerar lucro, isto quer dizer que o lucro econômico torna-se zero. Quando o rendimento da máquina alcança este ponto, significa que o equipamento tornou-se tecnologicamente obsoleto. O lucro é o estímulo para o empresário investir em 'novas máquinas', substituindo as não lucrativas, gerando o crescimento da produtividade, consequentemente da renda nacional. Essa substituição representa um investimento na modernização do capital que faz crescer a produtividade da economia. ${ }^{9}$

Além do incentivo do lucro, o processo de substituição das máquinas, i.e., a modernização do estoque de capital, pode acelerar-se quando: o salário real aumentar mais rápido que a produtividade, ${ }^{10} \mathrm{e}$ (ii) a 'taxa de incorporação tecnológica' se acelerar, isto é, o ritmo que novas máquinas vão aparecendo no mercado, em um período de tempo menor, em função de uma incorporação mais rápida das últimas inovações tecnológicas. O inverso provocaria um alargamento da vida econômica do capital (atrasaria a obsolescência tecnológica do capital). ${ }^{11}$ Do ponto de vista da competição internacional, o alargamento da vida econômica do estoque de máquinas doméstico poderia

8 Termo empregado por Kaldor e Mirrlees quando a lucratividade da máquina torna-se zero. Assim, o bem de capital estaria em operação somente enquanto sua receita cobrir largamente, ou no mínimo igualmente, os custos variáveis.

9 Kaldor e Mirrlees (1962), assim como em Kaldor (1957), sustentam que a taxa de crescimento da produtividade, como o próprio progresso técnico, seriam endógenos à taxa de crescimento do investimento por trabalhador. Contudo, há uma parte do progresso técnico que é devido ao aperfeiçoamento dos trabalhadores.

10 Isso pode ocorrer quando os bens salários ficarem relativamente mais caros que os bens de capital e quando houver uma apreciação cambial da moeda local, no caso de um modelo com a economia aberta.

11 No entanto, esta taxa de incorporação tecnológica depende da natureza do bem de capital a qual é incorporada. Bens de capital de baixa intensidade tecnológica tendem a ter uma taxa mais lenta relativamente aos bens de capital com maior intensidade tecnológica. Por exemplo, a taxa de incorporação tecnológica nos bens de capital para a indústria de alimentos é comparativamente menor que na indústria aeronáutica. 
provocar perda de competitividade relativamente aos concorrentes estrangeiros.

Em suma, para Kaldor-Mirrlees (1962) a introdução de máquinas e equipamentos de última geração seria fundamental para determinar o ritmo de crescimento econômico. Se, por um lado, estes investimentos ampliam a capacidade produtiva e aumentam a produtividade agregada, por outro, ao representar um aumento na demanda da indústria de bens de capital poderiam acelerar o compasso com que as inovações são incorporadas às máquinas que o setor produz. O setor produtor de bens de capital, pela sua natureza dinâmica, tem participação decisiva na determinação do crescimento e desenvolvimento econômico e no tipo de inserção internacional de um país. Assim, o processo de industrialização em direção aos setores mais dinâmicos poderia permitir que o avanço tecnológico refletisse também em aumento dos salários ao invés de só redução de preços.

\section{Um Modelo de Acumulação com Restrição Externa Baseado em Kaldor-Mirrlees e Kaldor-Thirlwall}

Como foi visto na seção 2 , a taxa de crescimento do produto real que é compatível com o equilíbrio do balanço de pagamentos é dada pela Equação (9):

$$
y_{t}=\frac{\varepsilon_{t}}{\pi_{t}} z_{t}
$$

Por hipótese, a acumulação de capital não afeta a "lei de Thirlwall", haja vista que as elasticidades-renda das exportações e das importações dependem da estrutura produtiva, a qual é considerada como independente do ritmo de acumulação de capital. A Figura 1 ilustra a linha de equilíbrio do balanço de pagamentos (a reta com inclinação de $45^{\circ}$ ) estabelecida pela Equação (9). A região acima desta reta é de superávit externo, abaixo é de déficit externo. $\mathrm{O}$ ponto A representa uma situação de equilíbrio. 


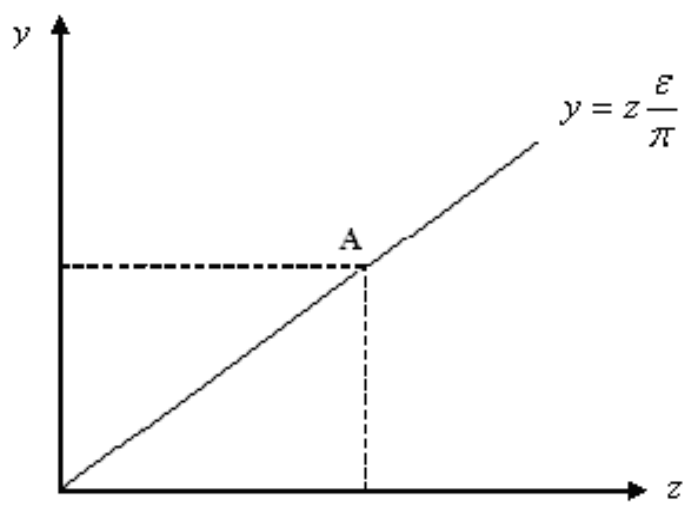

Figura 1 - Combinações Factíveis entre $y_{t}$ e $z_{t}$ e a Restrição Externa

Nosso objetivo a seguir é endogenizar as elasticidades-renda do modelo de Thirlwall, tornando-as dependentes da idade média do estoque de capital da economia, seguindo Kaldor-Mirrlees (1962). Assume-se que quanto mais moderno o equipamento de capital, maior será o conteúdo tecnológico da produção e, portanto, maior a elasticidade-renda das exportações e menor a elasticidade-renda das importações. Desse modo, é possível associar a taxa de crescimento compatível ao equilíbrio do balanço de pagamentos e a taxa garantida de crescimento. Assim, um aumento do esforço de acumulação de capital, com impacto sobre a estrutura produtiva conduziria, por intermédio da modernização do parque industrial, a um aumento do conteúdo tecnológico das exportações e, portanto, um aumento da elasticidade-renda das exportações e da taxa de crescimento compatível com o equilíbrio no balanço de pagamentos.

Portanto, assumimos que a razão entre as elasticidades está ligada ao hiato tecnológico, e tem uma relação inversa com a razão entre as vidas úteis dos equipamentos de capital da economia doméstica e estrangeira:

$$
\frac{\varepsilon_{t}}{\pi_{t}}=f_{1}\left[\frac{T_{t}}{T_{t}^{*}}\right], \quad f_{1}^{\prime}<0
$$


sendo $T_{t}$ a vida útil do equipamento de capital doméstico, e $T^{*}{ }_{t} \mathrm{o}$ equipamento de capital estrangeiro, e a relação entre as duas variáveis uma medida do hiato tecnológico. Logo, a estrutura produtiva de ambas as economias (doméstica e estrangeira) vai depender da idade média do estoque de capital de cada economia. ${ }^{12}$

Se $T>T^{*}$, ou seja, o intervalo de tempo após o qual a safra de equipamento de capital doméstico é substituída é maior do que no exterior, o ritmo de substituição do equipamento de capital doméstico é menor relativamente ao ritmo do exterior, e assim o progresso tecnológico avança mais rapidamente no exterior. Nesse sentido, ocorre um aumento do hiato tecnológico entre as economias. ${ }^{13} \mathrm{Com}$ este raciocínio podemos assumir uma relação inversa entre a variação entre as elasticidades-renda das exportações e das importações e a razão $T_{t} / T^{*}$. Suponha que ocorra uma queda na elasticidade-renda das exportações $\varepsilon$ relativamente à elasticidade-renda da importação $\pi$; neste caso assumimos que essa queda indica que a taxa de substituição de equipamento de capital na economia doméstica se tornou mais lenta do que na economia externa, ou seja, a razão $T_{t} /$ $T^{*}{ }_{t}$ aumenta. Portanto, se $T>T^{*}$, então, $\varepsilon<\pi$. O raciocínio inverso também se aplica. Com base no modelo de Kaldor-Mirrlees (1962), consideramos que:

$$
T=f_{2}\left(\frac{w_{t}}{q_{t}}\right), \quad f_{2}^{\prime}<0
$$

onde $w$ é a taxa de crescimento do salário real, e $q$ a taxa de crescimento da produtividade física do trabalho. ${ }^{14}$ Supondo que o salário real é exogenamente dado e uma taxa de câmbio fixa e igual a um,

12 Araújo e Lima (2007) também apresentam um modelo a partir da linha Kaldor-Thirlwall. Nela, "o crescimento [é] induzido por alterações na composição setorial da atividade econômica" (p.762). Os autores recuperam o Structural Economic Dynamic de Pasinetti para realizar uma análise macrodinâmica multisetorial. Assim, "mudanças na estrutura de produção levam a mudanças na taxa de crescimento", e desse modo, "diferenças nas estruturas de produção entre países implicam taxas de crescimento diferentes entre países. Onde os setores são caracterizados por diferentes taxas de crescimento da demanda, a estrutura de produção importa para o crescimento econômico agregado" (p.757).

13 Como em Cimoli (2005).

14 Em uma trajetória de crescimento de steady state, a taxa de crescimento da produtividade do trabalho cresce a uma taxa igual à taxa de crescimento do investimento (Kaldor e Mirrlees, 1962, p 63). Nos modelos de equilíbrio com restrição de balanço de pagamentos, a noção de steady-state também é usada, uma vez que se assume a constância dos termos de troca no longo prazo como condição necessária para a existência de uma trajetória de crescimento balanceado. 
podemos considerar a seguinte aproximação, com base em Foley e Michl (1999, p.25), e assumindo a plena utilização da capacidade produtiva (tal como no modelo Kaldor-Mirrlees), para expressar a taxa de lucratividade $r$ como:

$$
r=f_{3}\left(\frac{w_{t}}{q_{t}}\right), \quad f_{3}^{\prime}<0
$$

Considerando as Equações (12) e (13), temos:

$$
\frac{T_{t}}{T_{t}^{*}}=f_{4}\left(\frac{r_{t}}{r_{t}^{*}}\right), \quad f_{4}^{\prime}>0
$$

A Equação (14) mostra que a relação entre o período de vida útil do equipamento de capital doméstico relativamente ao equipamento de capital estrangeiro depende da relação entre a taxa de lucro doméstica e a taxa de lucro estrangeira. Se os custos salariais estiverem crescendo mais rapidamente na economia doméstica do que no exterior, então os capitalistas domésticos irão acelerar o investimento na modernização do equipamento de capital para assim obterem aumentos de produtividade que permitam a sustentação da taxa de lucro face ao movimento de elevação dos salários.

Dada essa hipótese, a diferença no hiato tecnológico entre dois períodos irá mostrar a relação do custo unitário por trabalhador doméstico vis-à-vis o custo unitário do trabalhador externo. Nesse modelo, quando a taxa salário cresce mais rápido que a taxa de crescimento da produtividade, os empresários, para se defenderem da queda de lucratividade, procurarão acelerar o ritmo de modernização do equipamento de capital. ${ }^{15}$ No modelo de Kaldor e Mirrlees, o salário tem uma correlação negativa com a vida útil da máquina, o que torna $T$ uma variável endógena. Quando o salário sobe, $r$ deverá cair porque $q$ é constante para cada 'safra' de máquinas, levando os empresários a substituírem as máquinas por uma da última safra, com uma produtividade maior, portanto $T$ irá cair.

15 Ver Marquetti (2004). 
Assumindo a existência de economias estáticas e dinâmicas de escala de tal forma que a taxa de crescimento da produtividade do trabalho em ambas as economias depende da taxa de crescimento do produto real, ou seja, assumindo a validade da "lei Kaldor-Verdoorn", onde $\alpha$ é a taxa de crescimento da produtividade autônoma e $\lambda$ é o coeficiente de Kaldor-Verdoorn. Assim, podemos escrever:

$$
\begin{aligned}
& q_{t}=\alpha+\lambda \cdot y_{t-1} \\
& q_{t}^{*}=\alpha+\lambda \cdot z_{t-1}
\end{aligned}
$$

Substituindo a taxa de crescimento da renda interna $(y)$ nas equações (15a) e (15b) pela taxa de acumulação de capital $(k)$ na equação de Kaldor-Verdoorn, temos para ambas as economias que:

$$
\begin{aligned}
& q_{t}=\alpha+\lambda \cdot k_{t-1} \\
& q_{t}^{*}=\alpha+\lambda \cdot k_{t-1}^{*}
\end{aligned}
$$

Substituindo a Equação (11) em (14) temos que:

$$
\frac{\varepsilon_{t}}{\pi_{t}}=f_{5}\left(\begin{array}{c}
\frac{r_{t}}{*} \\
r_{t}
\end{array}\right), \quad f_{5}^{\prime}<0
$$

Dessa forma, substituindo a Equação (17) na Equação (9) e fazendo as devidas transformações, tem-se:

$$
\frac{y_{t}}{z_{t}}=f_{6}\left(\begin{array}{c}
\frac{r_{t}}{*} \\
r_{t}
\end{array}\right), \quad f_{6}^{\prime}<0
$$

Finalmente traduzimos, conforme nossas hipóteses sobre a estrutura da economia, a equação de crescimento com restrição de balanço de pagamentos. A Equação (18) mostra que quanto mais alta a taxa de lucro doméstica vis-à-vis a taxa de lucro externa, menor o ritmo de modernização do estoque de capital doméstico vis-à-vis o exterior. Isso implica uma menor taxa de crescimento do produto doméstico 
com relação à taxa de crescimento do resto do mundo. Com a taxa de lucro na economia doméstica mais alta, os empresários ficam menos propensos a investir na modernização do estoque de capital da economia. Desse modo, o modelo pressupõe a inovação induzida como um elemento passivo ao investimento em capital. O hiato tecnológico determina a diferença entre as elasticidades-renda das exportações e importações e este, por sua vez, depende da relação entre as vidas úteis do equipamento de capital.

\subsection{A Dinâmica do Modelo}

Para avaliarmos a dinâmica de crescimento da economia, partimos da hipótese de que a taxa de crescimento da capacidade produtiva (ou produto potencial), $\bar{y}$, é proporcional à taxa de crescimento do estoque de capital $k$, conforme Domar (1946). Assim escrevemos:

$$
\bar{y}=\sigma \cdot k
$$

onde $\sigma$ determina o ritmo de crescimento e é denominado de produtividade social do capital. Aplicando a relação da Equação (19) às taxas de crescimento das rendas internas e externas, temos que:

$$
\frac{\bar{y}_{t}}{\bar{z}_{t}}=\sigma \frac{k_{t}}{k_{t}^{*}}
$$

No que se refere ao ritmo desejado de crescimento do estoque de capital pelos empresários, iremos assumir que o mesmo possui dois componentes: um autônomo, dado por $g_{0}$ e, $g_{1}$ dependente da relação entre a taxa de lucro doméstica e a taxa de lucro prevalecente no resto do mundo. ${ }^{16}$ Dessa forma, temos que:

$$
\frac{k_{t}}{k_{t}^{*}}=g_{0}+g_{1}\left(\frac{r_{t}}{r_{t}^{*}}\right)
$$

16 A estrutura de acumulação de capital segue a tradição do modelo Harrod-Domar, que ignora o capital financeiro, ou seja, não há financiamento externo à empresa. Este, portanto, é feito com os lucros retidos da firma. 
Para que haja crescimento balanceado no longo prazo é necessário que a taxa de crescimento do produto seja igual à taxa de crescimento da capacidade produtiva (ou das respectivas rendas internas e externas). Mais precisamente temos que:

$$
\frac{y_{t}}{z_{t}}=\frac{\bar{y}_{t}}{\bar{z}_{t}}
$$

Das Equações (20), (21) e (22), temos:

$$
\frac{y_{t}}{z_{t}}=\sigma\left[g_{0}+g_{1}\left(\frac{r_{t}}{r_{t}^{*}}\right)\right]
$$

A Equação (23), ilustrada na Figura 2, nos fornece-nos a relação entre as taxas de crescimento da economia doméstica e do resto do mundo, quando a economia doméstica se encontra numa trajetória de crescimento balanceado. Nessa trajetória, a produção e a capacidade produtiva se expandem a mesma taxa. Trata-se, portanto, de um conceito equivalente ao conceito de "taxa garantida de crescimento" do modelo do Harrod (1939).

As Equações (18) e (22) formam um sistema dinâmico com duas equações e duas variáveis endógenas, a saber: a estrutura relativa de taxas de lucro e a estrutura relativa de taxas de crescimento. A determinação das variáveis endógenas do sistema pode ser visualizada por intermédio da Figura 2 abaixo. 


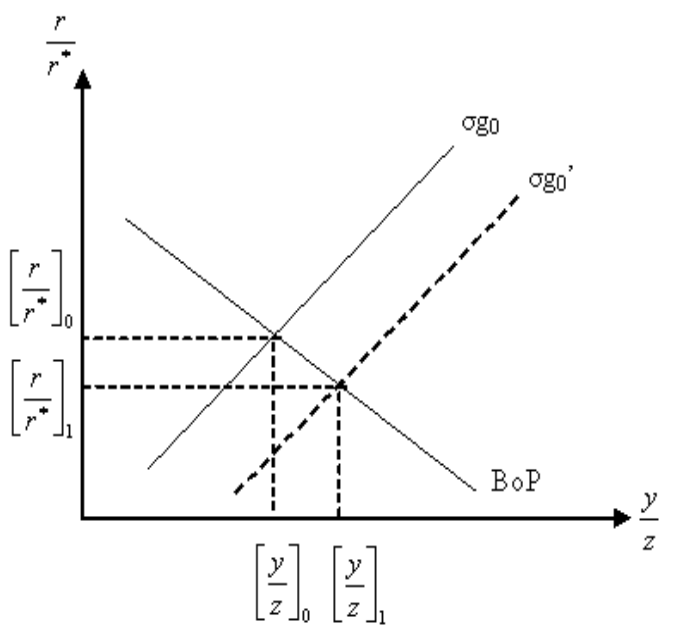

Figura 2 - Crescimento Balanceado com Mudança Estrutural

A Figura 2 mostra o que acontece na dinâmica de crescimento se houver um aumento exógeno do ritmo desejado de acumulação de capital por parte dos empresários, ou seja, um aumento do investimento autônomo. Esse aumento irá deslocar o lócus do crescimento balanceado para baixo e para a direita, aumentando assim a taxa de crescimento da economia doméstica relativamente à prevalecente no resto do mundo. No entanto, essa aceleração da acumulação de capital provocará, inicialmente, um desequilíbrio no balanço de pagamentos na forma de déficit na conta de transações correntes.

Para que o equilíbrio externo seja restabelecido é necessário que a taxa de lucro doméstica se reduza relativamente à taxa de lucro prevalecente no exterior para, dessa forma, induzir investimentos em modernização do equipamento de capital, os quais irão aumentar a produtividade do equipamento de capital na economia doméstica, atuando assim no sentido de contrarrestar a queda da lucratividade. Acontece que o maior investimento na modernização do equipamento de capital irá atuar no sentido de reduzir o hiato tecnológico, acarretando assim um aumento da razão entre a elasticidade-renda das exportações e a elasticidade-renda das importações. Dessa forma, ocorre uma mudança estrutural na economia doméstica, a qual atua no sentido de aumentar a taxa de crescimento que é compatível com o equilíbrio do balanço de pagamentos. 
Dessa argumentação, podemos concluir que a restrição externa ao crescimento de longo prazo pode ser relaxada por intermédio de uma mudança estrutural que reduza o hiato tecnológico entre a economia doméstica e o resto do mundo, mudança essa que é induzida por um maior esforço de acumulação de capital por parte dos empresários domésticos. Segue-se, portanto, que a acumulação de capital é o motor do crescimento de longo prazo para aqueles países que se encontram atrás da "fronteira tecnológica".

\section{Acumulação de Capital e Mudança Estrutural: A Experiência Brasileira (1950-1980)}

Do pós-guerra até 1980 o crescimento da economia brasileira, liderado pela acumulação de capital, deu-se a taxas elevadas. Durante as três décadas e meia desde o fim da Grande Guerra, três planos econômicos de cunho desenvolvimentista foram implementados Plano de Metas (1956-61) e os I (1968-73) e II (1974-79) Planos Nacionais de Desenvolvimento - que contribuíram para promover significativas mudanças na estrutura produtiva do país. Apesar destas medidas, a economia brasileira permaneceu fechada (o processo de abertura comercial se iniciou no final dos anos 1980), e, portanto, caracterizada por muitos analistas como com uma dinâmica de crescimento "voltada para dentro". Como veremos, o relativo fechamento da economia brasileira, após ter passado por um processo acentuado de mudança estrutural com aumento do seu potencial de crescimento, pode ser apontado como sendo o ponto fraco na estratégia de industrialização, que foi interrompida no final dos anos 1970.

$\mathrm{Na}$ medida em que as mudanças na estrutura produtiva resultaram de um processo de substituição de importação, que implica um esforço concentrado de acumulação de capital em espaço de tempo relativamente curto, consideramos a economia brasileira no período do pós-guerra até 1980 um caso interessante para ilustrar a relevância do modelo teórico desenvolvido anteriormente. Neste modelo buscou-se estabelecer uma ligação lógica entre a aceleração do crescimento promovida pelo aumento da acumulação de capital e a mudança na estrutura produtiva. Como todo modelo teórico, o proposto não descreve estritamente uma realidade específica, porém acreditamos que destaca argumentos relevantes que podem ser usados para 
descrever a dinâmica da industrialização brasileira, em que o crescimento acelerado possibilitou uma mudança estrutural que permitiu relaxar temporariamente a restrição ao crescimento.

O elevado ritmo de crescimento do pós-guerra até 1980 - taxa média de crescimento acima de $6 \%$ a.a. -, situou o desempenho da economia brasileira em patamar superior ao do conjunto dos países desenvolvidos e em desenvolvimento. Esse crescimento foi interrompido com a crise da dívida externa em 1980-81, que trouxe constrangimentos ao tipo de financiamento empregado pela política desenvolvimentista adotada até então. ${ }^{17}$

A fase de crescimento acelerado foi caracterizada por intensa substituição de importações e, portanto, de consolidação do parque manufatureiro nacional. Os períodos de maior aceleração do crescimento - 1957-62 e 1968-74 - coincidiram com elevada liquidez internacional, indicando que o processo de substituição de importações foi em grande medida financiado com poupança externa.

A Tabela 1 ilustra a transformação na estrutura produtiva, com a indústria como um todo aumentando sua participação no PIB, passando de 26,0\% em 1947 para 44,1\% em 1980. Em termos das indústrias de transformação e extrativa os percentuais passaram de 20,3\% para $34,8 \%$, respectivamente. Este aumento de participação colocou o setor no papel de liderar o crescimento da economia, com expansão média de $8,6 \%$ a.a. de 1947 a $1980 .^{18}$

O aumento na participação da indústria na economia também foi acompanhado de ampla diversificação de sua estrutura. A década de 1970, de ritmo de crescimento mais intenso da indústria, marca a consolidação na produção de segmentos de bens duráveis e intermediários, completando o processo de substituição de importações conforme a implementação dos planos nacionais de desenvolvimento

17 De 1980 até 2008, a taxa média de crescimento do PIB girou em torno de 2,7\% a.a, com as prioridades de política econômica voltadas, em grande medida, para a estabilização de preços e controle das contas externas. Apenas a partir de 2004 evidencia-se um novo ciclo expansivo na economia brasileira, porém este foi temporariamente interrompido pela crise financeira internacional que atingiu principalmente a indústria de transformação no último trimestre de 2008. Considerando o crescimento do PIB neste último período (2004-2008), a taxa média de crescimento foi de $4,7 \%$ aa, com a taxa de investimento se elevando de 15,5\% em 2004 para 18,5\% em 2008.

18 Essa expansão não foi contínua no tempo, valendo destacar o período de 1963-67 como o de menor dinamismo (crescimento médio de 2,7\% a.a.). A partir de 1968 se inicia a fase de crescimento mais acelerado, com a indústria crescendo $9,8 \%$ a.a. 
(PND I -1968-73 e PND II - 1974-79). Em 1980, mais de 50\% do valor adicionado das indústrias de transformação e extrativa correspondiam à fabricação de produtos classificados como intensivos em escala $(38,6 \%)$, diferenciados $(11,7 \%)$ e baseados em engenharia $(2,8 \%)$.

Tabela 1 - Participação (\%) de Ramos de Atividade no PIB (1947, 1960, 1970, 1980)

\begin{tabular}{lcccc}
\hline Classes e Ramos de Atividade & 1947 & 1960 & 1970 & 1980 \\
\hline Agropecuária & 21,4 & 18,3 & 12,3 & 10,9 \\
Indústria & 26,0 & 33,2 & 38,3 & 44,1 \\
Transformação e Extrativa & 20,3 & 27,1 & 30,1 & 34,8 \\
Construção & 4,6 & 5,0 & 5,8 & 7,3 \\
Serviços Industriais de Utilidade Pública & 1,1 & 1,1 & 2,4 & 1,9 \\
Serviços & 55,7 & 51,5 & 56,2 & 52,7 \\
\hline
\end{tabular}

Fonte: IBGE, Contas Nacionais, Sistema Consolidado.

A maior presença do setor industrial na estrutura produtiva implicou também a diversificação das exportações: em 1964 a participação de manufaturados e semimanufaturados somava $14 \%$ e em 1980 este percentual elevou-se para 57. ${ }^{19}$ Mesmo com este avanço na pauta de exportação, a participação das exportações no PIB situouse abaixo dos $10 \%$ durante todo o período, a menos dos 2 primeiros anos do pós-guerra a partir dos quais se tem informação estatística. Conforme mencionado, a estratégia de industrialização via substituição de importações implicou relativo fechamento da economia e, portanto, o coeficiente de importação (participação da importação no total do comércio externo) girou em torno de 50\% até 1970, ampliando-se na década de 1970 , em particular após o $1^{\circ}$ choque do petróleo. A média deste coeficiente no período 1947-80 foi de $52 \% .{ }^{20}$

A taxa de investimento por sua vez apresentou trajetória crescente, partindo de 14,7\% em 1947 e atingindo a 24,0\% em 1980. Assim, o crescimento econômico foi puxado pela acumulação de capital. O

19 Vale registrar também que com a crise da dívida externa nos anos 1980, considerando só as exportações de manufaturados, estas atingiram a mais de $50 \%$ da pauta em 1981, cifra que se manteve nesse patamar ou acima até 2008 , quando caiu para $47 \%$.

20 Na década de 1980, devido ao ajuste na estrutura produtiva ocasionado pela restrição externa, esta média caiu para $40 \%$. 
financiamento deste processo se fez com recursos externos e estatais e é na relação com o setor externo que o modelo de industrialização brasileiro mostrou seu ponto de maior fragilidade.

Traduzindo a performance da economia brasileira vista até aqui à luz do modelo proposto na seção anterior, observamos que, um aumento na taxa de acumulação da economia brasileira desde o pós-guerra, aumentou seu potencial de crescimento e reduziu o hiato tecnológico. No entanto, conforme ilustrado na Figura 2, a aceleração no processo de acumulação de capital causa desequilíbrios no Balanço de Pagamentos na forma de geração de déficits em conta corrente. Para se restabelecer o equilíbrio externo de forma a compatibilizálo como o maior potencial de crescimento, é necessário que o setor externo se torne mais competitivo. Observando o caso brasileiro, isto implica dizer que a estratégia de substituição de importação deveria ter alcançado também o setor produtor de bens de capital e setores mais intensivos em tecnologia, para aumentar a elasticidade renda das exportações em relação à elasticidade-renda das importações de forma a restabelecer o equilíbrio externo compatível com o maior potencial de crescimento econômico. De acordo com o modelo original de Kaldor-Mirrlees, o incentivo para investir em equipamentos novos e mais produtivos viria da queda da taxa doméstica de retorno relativamente aos países desenvolvidos. O modelo proposto sugere que no caso da economia brasileira as taxas de retorno foram mantidas relativamente elevadas devido, dentre outros fatores, à distribuição funcional da renda desfavorável aos salários, ${ }^{21}$ o que não contribuiu para promover o catching up.

Recuperando os argumentos teórico-conceituais apresentados na seção 3, uma estrutura produtiva onde predominam setores com vantagens comparativas na produção de bens intensivos em recursos naturais e de baixa intensidade tecnológica pode sustentar altas taxas de crescimento durante um certo período de tempo. Se se dispõe de recursos externos, que financiem as importações decorrentes das altas taxas de crescimento domésticas, a duração desse período pode ser ampliada. Porém, ao se recorrer ao endividamento externo, devese atentar para os efeitos negativos deste processo, conforme apontado por Moreno-Brid (1998-99). À medida que o endividamento se eleva, o grau de vulnerabilidade da economia aumenta, tornando-a

21 De acordo com as Contas Nacionais, a participação dos salários no total da Renda Nacional caiu de 40,7\% em 1970 para 38,4\% em 1980. 
sujeita à reversão em sua trajetória de crescimento, caso ocorram variações adversas nas condições de financiamento no mercado financeiro internacional. Este foi o caso do crescimento brasileiro e de outras economias latino-americanas no início dos anos 1980 que viram suas trajetórias de crescimento interrompidas com o episódio da moratória mexicana em 1982.

O Gráfico 1 ilustra a evolução da Balança Comercial e da Conta de Capital e Financeira de 1947 até 1985. O período de aceleração do crescimento econômico, principalmente a partir de 1974-80, coincide com o aumento da absorção de poupança externa, possibilitado pela elevada liquidez internacional. A interrupção dos fluxos financeiros a partir de 1982 leva a uma contração na demanda interna e em sequência o registro de elevados superávits na Balança Comercial. Para Castro e Souza (2004), os elevados superávits comerciais foram possibilitados pelas mudanças estruturais engendradas pelo II PND na indústria brasileira. Tão logo o problema externo foi equacionado pelo aumento das exportações, como ocorreu entre 1984-1985, taxas positivas e expressivas de crescimento do PIB voltaram a ocorrer (com efeito, as taxas de crescimento do PIB em 1984, 1985 e 1986 foram 5,4\%; 7,8\% e 7,5\% respectivamente). Esta retomada apontava para a trajetória ascendente como aquela entre 1950-1980. Depois deste momento heroico que se seguiu após a recessão do início da década, as taxas de crescimento, parafraseando Castro (2008), beiraram a semiestagnação.

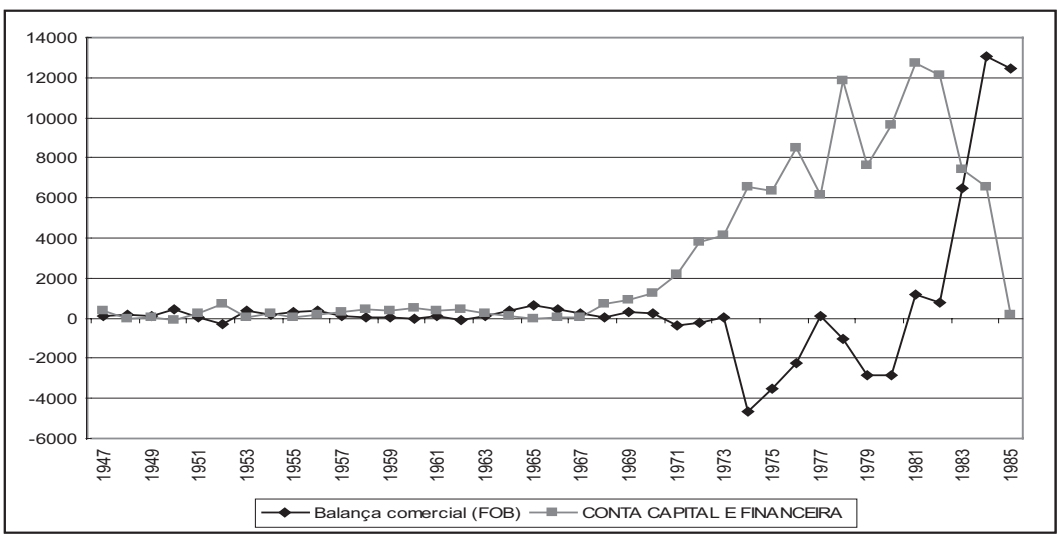

Gráfico 1 - Saldo da Balança Comercial e da Conta de Capital e Financeira US\$ milhões

Fonte: Banco Central do Brasil. 
A queda na taxa de acumulação de capital que se evidencia na economia brasileira nas décadas seguintes contribuiu para que a evolução da estrutura produtiva não se desse no sentido de relaxar a restrição de equilíbrio do balanço de pagamentos, conforme previsto no modelo Kaldor-Thirwall. Esta limitação do processo de crescimento econômico das últimas duas décadas e meia, em um contexto de maior integração das economias, coloca com maior relevância a necessidade de se reduzir o hiato tecnológico como requisito para se elevar a taxa de crescimento de longo prazo da economia brasileira.

\section{Conclusões}

Ao longo deste artigo argumentamos que a restrição externa ao crescimento de longo prazo - representada pela razão entre as elasticidades-renda das exportações e das importações - pode ser relaxada por intermédio de um esforço de acumulação de capital que proporcione uma mudança estrutural nas economias periféricas, de tal sorte a reduzir o hiato tecnológico.

Com base na literatura estruturalista-evolucionista argumentamos que o padrão de especialização de um país está relacionado com o nível de desenvolvimento tecnológico. Países desenvolvidos possuem um número maior de setores de atividade nos quais as firmas operam na "fronteira tecnológica" porque possuem uma base (benchmark) de desenvolvimento tecnológico maior que os países em desenvolvimento. Assim, as exportações dos países desenvolvidos são majoritariamente de produtos de alto valor adicionado e alto conteúdo tecnológico. O desenvolvimento tecnológico corporificado na produção de bens de consumo e de capital leva a uma composição da estrutura industrial em que prevalecem setores com maior intensidade tecnológica. Para o crescimento de longo prazo, supõe-se que o efeito do desenvolvimento local de tecnologia seja mais consistente que a importação da mesma.

Nesta perspectiva, para que ocorra uma redução do hiato tecnológico é necessário que as economias periféricas sejam capazes de transformar sua estrutura produtiva em direção a setores cujas rendas sejam derivadas da exploração de conhecimento, em detrimento de setores cujas rendas são derivadas da abundância de algum fator de produção. Nesse sentido, observamos que a existência de recursos 
naturais e trabalho abundantes são, em si mesma, insuficientes para sustentar o crescimento de longo prazo. Desta forma, economias especializadas em setores de baixa elasticidade-renda da demanda estão mais expostas a desequilíbrios externos que se traduzem em taxas de crescimento do produto mais baixas.

Para formalizar a relação entre mudança estrutural e acumulação de capital foi desenvolvido um modelo baseado nas contribuições de Kaldor do final dos anos 1950 e início dos anos 1960, em que o investimento em modernização do equipamento de capital permite a absorção de novas tecnologias possibilitando assim a produção de bens com conteúdo tecnológico crescente; e dos anos 1970, quando a restrição de demanda imposta pelo equilíbrio do balanço de pagamentos é trabalhada. O modelo de crescimento proposto com essas características pode ser considerado 'híbrido'. O modelo teórico mostrou a possibilidade lógica de um aumento da taxa desejada de acumulação de capital permitir, por intermédio da modernização do equipamento de capital existente, aumentar o conteúdo tecnológico da produção doméstica, aumentando assim a elasticidade-renda das exportações e reduzindo a elasticidade-renda das importações.

A experiência histórica da economia brasileira no período 1950-1980 ilustra a validade da hipótese sugerida ao longo deste trabalho. Com efeito, a economia brasileira passou, nesse período, por uma grande mudança estrutural induzida pela acumulação de capital. Essa mudança estrutural permitiu um relaxamento, ainda que parcial e temporário, da restrição externa ao crescimento, viabilizando a ocorrência de taxas elevadas de crescimento do produto real.

No que diz respeito à aceleração da acumulação de capital esta se deu, na sua maior parte, com investimento autônomo, tanto do Estado como pela entrada de investimento estrangeiro direto. Esta realidade não se configurou a partir dos anos 1980, quando a crise da dívida externa desencadeou uma série de desequilíbrios macroeconômicos que reverteram a tendência de crescimento da economia brasileira. $\mathrm{Na}$ fase de crescimento acelerado, o hiato tecnológico diminuiu, mas a ausência de consolidação de uma produção local de tecnologia face às restrições externas posteriores, impediu que o hiato continuasse se reduzindo. Após a abertura econômica nos anos 1990 o que se evidencia é um aumento do grau de especialização da estrutura produtiva em recursos naturais. 


\section{Referências}

Araujo, R.A. and Lima, G.T. (2007) A Structural Economic Dynamic Approach to Balance-of-PaymentsConstrained Growth. Cambridge Journal of Economics, $\mathrm{n}^{\circ} 31$.

Atesoglu, H.S. (1997). Balance of Payments-Constrained Growth Model and Its Implications for the U.S. Journal of Post Keynesian Economics, Vol. 19, n.3.

BCB: Balanço de Pagamentos

Castro, A. B. e Souza, F. E. P. (2004). A economia Brasileira em marcha forçada, Editora Paz e Terra, $3^{\mathrm{a}}$. ed.

Castro, A B. (2008). From Semi-stagnation to Growth in a Sino-centric Market. Revista de Economia Politica, 28 (1).

Cimoli, M (2005). Heterogeneidad Estructural, Asimetrías Tecnológicas y Crecimiento en América Latina, CEPAL.

Cimoli, M., Porcile, G., Primi, A. e Vergara, S. (2005). Cambio Estructural, Heterogeneidad Productiva y Tecnología en América Latina. In: Cimoli, M. (editor) Heterogeneidad estructural, asimetrías tecnológicas y crecimiento en América Latina, CEPAL.

Domar, E. (1946). Capital Expansion, Rate of Growth and Employment. Econométrica, vol. 14, pp 137-147.

Dosi, G., Pavitt, K.; Soete, L. (1990). The Economics of Technical Change and International Trade, New York University Press.

Dutt, A.K. (2003). Income Elasticity of Imposts, North-South Trade and Uneven Development. In: Dutt, A.K; Ros, J. (orgs.). Development Economics and Structuralist Macroeconomics. Edward Elgar: Aldershot.

Fagerberg, J. (1988) Why Growth Rates Differ. In: Dosi, G et al. (orgs.). Technical Change and Economic Theory. Pinter Publishers: Londres.

Fajnzylver, F. (1983) La Industrialización trunca de América Latina. Editorial Nueva Imagem, México.

Fajnzylber, F (2000) O Conjunto Vazio, em Cinqüenta anos de Pensamento na Cepal. Org, Bielschowky, R. Editora Record, volume 2.

Foley, D; Michl, T. (1999). Growth and Distribution. Harvard University Press: Cambridge (Mass).

Furtado, C (1984) Cultura e Desenvolvimento em Época de Crise. Editora Paz e Terra, Rio de Janeiro.

Furtado, C [1952](2010) Formação de Capital e Desenvolvimento Econômico, em A Economia do Subdesenvolvimento. Org: Agarwala, A.N. e Singh, S.P. Editora Contraponto, Rio de Janeiro. Centro Internacional Celso Furtado.

Harrod, R (1933) International Economics, Cambridge, Cambridge University Press.

Harrod, R (1939). An Essay in Dynamic Theory. The Economic Journal, vol. 49, 1939.

Holland, M; Porcile, G (2005). Brecha Tecnológica y Crecimiento en América Latina. In Cimoli, M. (org.) Heterogeneidad estructural, asimetrías tecnológicas y crecimiento en América Latina, CEPAL.

IBGE: Contas Nacionais, sistema consolidado.

IBGE: Censo Industrial de 1970 e 1985

Kaldor, N. (1957) A Model of Economic Growth. Economic Journal.

Kaldor, N; Mirrlees, J.A. (1962). A New Model of Economic Growth. Review of Economic Studies, 29.

Marquetti, A (2004). Do rising Real Wages Increase the Rate of Labor-Saving Technical Change? Some Econometric Evidence. Metroeconomica, Vol. 55, N.3.

McCombie, J.L; Roberts, M. (2002). The Role of the Balance of Payments in Economic Growth. In Setterfield, M. The Economics of Demand-led Growth: Challenging the supply-side vision of the long run. Edward Elgar. 
Moreno-Brid, J.C. (1998-1999). On Capital Flows and the Balance of Payments Constrained Growth Model. Journal of Post Keynesian Economics, Vol. 21, N.2.

Prebisch, R. (2000) Problemas Teóricos e Práticos do Crescimento Econômico, em Cinqüenta anos de Pensamento na Cepal. Org, Bielschowky, R. Editora Record, volume 1.

Rodriguez, O. (2009). O Estruturalismo Latino-Americano. Civilização Brasileira: Rio de Janeiro.

Tavares, M.C.(1976) Da Substituição de Importações ao Capitalismo Financeiro: ensaios sobre economia brasileira. Zahar Editores, Rio de Janeiro.

Thirlwall, A.P (1979). The Balance of Payments Constraint as an Explanation of International Growth Rates. Banca Nazionale del Lavoro. Quarterly Review, March.

-(1997). Reflections on the Concept of Balance of Payments Constrained Growth. Journal of Post Keynesian Economics

(2001). The relation between the warranted growth rate, the natural growth rate and the balance of payments equilibrium growth rates. Journal of Post Keynesian Economics.

Verspagen, B (1993). Uneven Growth Between Interdependent Economies. Avebury: Aldershot. 